\title{
Promoting Active Learning in Electrical Engineering Basic Studies
}

\author{
http://dx.doi.org/10.3991/ijep.v3iS3.2653 \\ A. Lehtovuori ${ }^{1}$, M. Honkala ${ }^{1}$, H. Kettunen ${ }^{2}$, and J. Leppävirta ${ }^{3}$ \\ ${ }^{1}$ Aalto University School of Electrical Engineering, Espoo, Finland \\ ${ }^{2}$ University of Helsinki, Helsinki \\ ${ }^{3}$ Outotec, Espoo
}

\begin{abstract}
Active learning, project-based teaching, and student collaboration are current trends in engineering education. Incorporating these have also been the goal of the basic studies development project EPOP started at the Aalto University School of Electrical Engineering in 2011. In the project, two obligatory basic courses in circuit analysis and electromagnetic field theory have been taught using interactive engagement during the spring of 2012. This paper presents the implementation of the teaching, including methods and evaluation with several concrete examples. As a result of the novel teaching, motivation and the engagement of students were at a high level during the whole course and learning results were better than those of the students participating the traditional lecture course
\end{abstract}

Index Terms-Group work, interactive engagement, motivation, peer instruction.

\section{INTRODUCTION}

Engineering education is under pressure to change [e.g., 1-6]. More effort should be channeled into motivating and attracting students and to engage them in their studies and the learning process. At the same time, the significance of professional skills and life-long learning are emphasized. Traditional engineering teaching methods, such as lectures, exercises and lab work have been criticized because they do not prepare engineering students to collaborate and to learn active learning behavior, which emphasize interaction between students. In addition, conceptual thinking is now considered more important than before. Understanding the central ideas of the domain, comprehending the relationships between basic concepts, and applying central relationships in problem solving should be encouraged. Professional life today is increasingly interdisciplinary and challenges engineers to learn to interact with others, to give and accept criticism, and also to listen to and understand alternative viewpoints. However, collaboration is a process, and students need help to practice teamwork skills like conversing and listening, leadership, conflict management, decision making, confidence building, and finding compromises.

Circuit analysis 2 and Dynamic field theory are obligatory 5-credit courses for all electrical engineering students in Aalto University School of Electrical Engineering (ELEC). Due to the large number of students, these courses are normally taught in the traditional form with lectures, exercises, homework, and exams. Both courses have two hours of lectures and two of exercises per week. The basic studies development project EPOP started in 2011 at the Aalto University School of Electrical Engi- neering, where these two courses were merged into the EPOP course trying to create larger subject entities and helping students to connect issues together. Earlier results and positive feedback obtained from the application of the problem-based learning (PBL) approach to the Circuit Analysis courses [7] encouraged the use of interactive teaching methods. In the EPOP course, instruction was given to a group of 20 students using interactive and motivating multiform teaching in order to engage students and to add enthusiasm to learning. Many different and versatile teaching methods were used including laboratory work, simulation exercises, collaborative calculation exercises done in small groups, and larger projects.

The main focus of this paper is the practical implementation of the EPOP course, because far too often only the methods and results are reported without a concrete description of the actual course work. However, the lack of appropriate teaching material is the biggest barrier to apply these methods in practice [6]. Therefore, here the authors aim to give a concrete and detailed description of the practical implementation of the teaching. Also, teaching results are compared to those of the traditional lecture courses. This paper first discusses the goals of the integration and the renewal process. Next, the practical implementation of the teaching is presented with several examples of exercises used during the course. Finally, the evaluation of students and a reflection on the teaching are collected in Sections IV and V.

\section{OBJECTIVES OF THE TEACHING}

Circuit analysis 2 and Dynamic field theory are heavy basic courses that include a large amount of quite hard theoretical content. The Circuit analysis 2 course includes, e.g. time-domain analysis using the Laplace transform; driving-point and transfer functions; $z, y-$ and chain parameters for two-ports; and, in addition, also transmission lines in the time and frequency domain and impedance matching with the Smith chart. The Dynamic field theory course consists of Maxwell's equations in dynamics, Faraday's law, time-harmonic fields, eddy currents, electromagnetic waves in free space and in closed structures, reflection and transmissions waves, and the basics of antennas.

The goal of EPOP project was to integrate these two courses together and to increase the teaching focus on hands-on engineering skills: laboratory measurements and using simulation software. Also, teaching methods for collaborative learning were added to increase the motivation to study. Large basic courses have many known 
problems which are mainly a consequence of the large number of students compared to resources available, as described also in [8].

The purpose of combining the courses was to find relevant common themes to provide a framework and motivation for teaching and learning. The following six topics were chosen:

1. Transient phenomena

2. Electromagnetic spectrum

3. Reflection, transmission, transmission lines and the TEM wavemode

4. TE and TM wavemodes and resonators

5. Two-port

6. Antennas

These larger themes aim to engage students in their studies and encourage critical thinking and scientific reasoning. In practice, the students solve problems and participate in small projects in groups of 2-3 persons.

Courses with this kind of conceptually complex content are not perceived as motivating among students, and as a consequence, there are also many drop-outs. This is partly due to inadequate prerequisite knowledge. Without strong mathematical skills, the workload of the courses increases quite a bit. Even the easiest problems can cause insuperable difficulties if students' mathematical background is poor and they are unfamiliar with differential equations, the Laplace transform, and vector algebra. Despite recognizing this problem, the large number of students restricts the amount of individual guidance that can be given during the course. In addition, large course content does not enable the use of much time for motivating students.

The renewal of the bachelor study program in Aalto University put pressure but also presented the perfect opportunity to make larger changes to existing courses. The EPOP project provided the possibility to renew teaching, test ideas beforehand, and to find means, to implement good practices in large courses also. Therefore, the EPOP project had many goals in addition to the normal course objectives.

First, the authors want to increase collaboration with and between students. Our studies are accused of being non-engaging, including too much self-study, of leaving students alone, and lacking the cooperation. These challenging issues, also discussed in $[4,5]$ can partly lead to dropping out from the courses. Additionally, the study progress will be an essential meter of the school's budget funding, which increases the school's responsibility of students. Getting a social network of friends, working together, and being in tighter contact with the teaching staff can improve study progress. These factors are especially important with first-year students, who should be helped to build their peer networks. Adopting group work as a part of teaching is one of the means recommended, because the amount of interaction among students as well as between students and staff remarkably affects to the learning outcomes also. Almost any form of student involvement benefits learning [9]. Similarly, the group work enhances students' professional skills, which is a part of the official learning outcomes of the academic degree.

Therefore, the authors wanted to test new teaching methods and get more familiar with different group guidance methods. Finding good practices which encour- age collaboration was the main focus. However, it is important to be aware that collaborative activities are not always successful $[6,10]$. Comprehension and achievements are not guaranteed to improve simply by putting students to work near each other. When planning the teaching, creating the right atmosphere for collaborative teaching is important. A competitive class environment can be a barrier for collaboration [1]. The prerequisites for successful cooperation are a common goal for working and sufficiently open problems with multiple approaches or solutions [2].

This project also provided a chance to prepare new laboratory and simulation exercises. In order to encourage cooperation, it is important to use wider problems with several possible solutions. Designing workable, educational, and motivating new exercises which are strictly connected to the theory and learning outcomes takes a surprisingly long time. Sometimes teacher's good ideas work not with students, so possibility to test exercises in smaller student group and get feedback of them is worth using of help.

Continuous evaluation during a course has been experienced as motivating, and it supports regular study habits, issues which are not self-evident to the first year students. Therefore, student evaluation was considered to require a rethink. Instead of just an exam at the end of the course, project work, exercises, and participation in the course are also an essential part of the evaluation. Collaborative evaluation of the project work is applied in order to motivate cooperation, but exams are evaluated individually in order to prevent free riding.

Finally, comes the project's aim to strengthen students' conceptual thinking. Interaction between procedural and conceptual knowledge has been studied quite a lot, as reported, e.g., in [11]. Improvement in students' conceptual thinking enhances also their skills to solve algebraically involved problems. Conceptual knowledge helps students to understand purposes and reasons, which facilitates learning procedural skills. When mathematical procedures are no longer unconnected pieces of information, it frees up the capacity for practicing solving procedures and makes them more automatic and fluent. Conceptual knowledge also enables to identify and apply calculation methods for solving problems and detect errors in calculations.

\section{PRACTICAL IMPLEMENTATION OF TEACHING}

The biggest challenge in adopting interactive teaching methods may be the lack of complete teaching material. Most papers on education research concentrate on the theory behind methods or they report the research of learning outcomes without giving any concrete examples of the exercises, questions, or task formulations. However, designing and implementing exercises which support and encourage interaction is probably the most challenging task. For this reason, a concrete and detailed description of the practical implementation is given here.

In spring 2012, eighteen students participated in the pilot EPOP course, which consisted of four two-hours sessions per week, some of which were reserved for selfstudy. Interactive engagement (IE) was applied in the teaching. It is a category of teaching methods that activates students to work together. IE forms an effective learning environment in science education based on 
research [12]. Regular and intensive interaction between students plays an important role where feedback and guidance is given not only by the teacher but also by other students. Continuous feedback supports the learning process. IE can be understood as a way to take advantage of interaction to enhance student learning. In practice, this means working heads-on and usually also hands-on. The goal is challenging students to do something that requires brainwork.

For all the six topics, students worked in small groups of 2-3 persons. For every topic, the groups were formed again using different rules (for example, free choice, a heterogeneous group based on achievements in former studies, or by drawing lots). Versatile teaching methods like laboratory measurements, simulations, and demos were used. The essential part of the student-centric teaching is doing and acting both alone and as a group member, where the teachers give guidance and feedback all the time. The peer instruction (PI) method and collaborative problem solving was used constantly during the course. Laboratory measurements (as group work) as well as simulation software were used frequently. For circuit simulation, the AWRDE software was utilized. The electromagnetic simulations were performed using COMSOL Multiphysics. Also, Matlab was used as a computational tool in some cases.

The schedule and methods used in EPOP are summarized in Table I to give an overview of the teaching methods and assessment used. Collaborative calculation exercises and PI were used regularly weekly and are, therefore, omitted from the list of teaching methods. Also participation in specified parts of teaching (simulations, demos, labs) was part of the achievement.

TABLE I.

SUMMARY OF THE EPOP COURSE

\begin{tabular}{|l|c|c|c|}
\hline \multicolumn{1}{|c|}{ Topic } & $\begin{array}{c}\text { Duration } \\
\text { (weeks) }\end{array}$ & $\begin{array}{c}\text { Teaching } \\
\text { methods }\end{array}$ & Assessment \\
\hline Transient & 3 & $\begin{array}{c}\text { Demos, } \\
\text { simulations, labs }\end{array}$ & Exam problem \\
\hline EM spectrum & 2 & Demos & $\begin{array}{c}\text { Exam problem, } \\
\text { learning diary }\end{array}$ \\
\hline $\begin{array}{l}\text { Transmission } \\
\text { lines }\end{array}$ & 3.5 & $\begin{array}{c}\text { Simulations, } \\
\text { labs }\end{array}$ & $\begin{array}{c}\text { Design exercise, } \\
\text { two exam } \\
\text { problems }\end{array}$ \\
\hline TE/TM & 1.5 & Simulations & $\begin{array}{c}\text { Simulation } \\
\text { exercise }\end{array}$ \\
\hline Two-port & 2 & Simulations, \\
labs & $\begin{array}{c}\text { Project work on } \\
\text { two-port }\end{array}$ \\
\hline Antennas & 2 & Simulations & $\begin{array}{c}\text { Design exercise, } \\
\text { exam problem }\end{array}$ \\
\hline
\end{tabular}

Special attention was paid to the quality of the exercises used. The exercises were designed so that they demand applying and combining learned topics and did not have only one strictly defined solution so that students are encouraged to integrate their ideas and collaborate. One important feature is that exercises cannot be divided into separate parts such that each team member could work on his or her own part individually.

The course also took place in a newly renovated classroom where the students were seated at round tables making them automatically form groups of 3-4 students, which was an ideal setup when considering collaboration. In the following, the teaching methods and some concrete examples of laboratory measurements, simulation exercis- es, design exercises, and demonstrations are presented, aiming to give clues and inspiration to teachers wanting to pop-up their classes.

\section{A. Demonstrations}

The first actual teaching session on the course was held in a student laboratory. Before any instruction on the theory, the students were given three simple demonstrational setups that were related to electromagnetic induction and Faraday's law. The demonstrations were not presented by the teacher, but the students had to discover the phenomena by themselves in groups of three students. They were asked to write down observations, prepare a report on one of the demonstrated phenomena, and explain the underlying theory. This was a clear way to wake the students up to notice that now the teaching is something out of the usual and their own activity is required. Instead of the traditional way to give first the general theory, the order was now reversed, and, the theory was constructed inductively based on experimental observations [13], which is the way many famous theories originally were formulated.

The first setup consisted of a strong permanent magnet and a self-made copper coil of two LEDs with different colors soldered at its ends in opposite directions [14]. When the magnet is moved in the vicinity of the coil, the flash of an LED indicates an induced electric current in the coil and the green or red color of the light its direction. With this setup, how the orientation of the magnet or the direction and speed of its movement affected the amplitude and the direction of the induced current can be studied.

The second setup consisted of a small permanent magnet and a hollow aluminum tube. When the magnet is dropped into the tube, the induced eddy currents begin to slow down its fall, being a classic example of magnetic braking [15].

The third setup was a simple electric motor, which was built out of a battery, a permanent magnet, a nail and a copper wire [16]. An electric current in a magnetic field experiences a force, which makes the motor rotate. Another, even simpler variation was also presented, where the magnet was attached to the battery and a rigid copper wire rotated around the battery. An Internet search 'homopolar motor' results in numerous video clips and instructions for building different variations of this motor.

\section{B. Peer Instruction with clickers}

Instead of conventional lecturing, one of the objectives of the EPOP project was to pilot new alternative ways of teaching. Theory of dynamic fields was mainly taught in eight contact teaching sessions where the peer instruction (PI) approach [17, 18] was applied. The PI method was introduced by Eric Mazur in the 1990's to enhance students' conceptual understanding by engaging them in discussion and making them teach each other. In short, the procedure is the following. The teacher poses the students a multiple-choice question, which all students first answer individually. Then, the students discuss their answers with each other in small groups trying to convince their partners about the correct answer and its reasoning. After the discussion, each student answers the same question once again. The number of correct answers is expected to increase after the discussion. 
In practice, PI is often implemented by using electrical response devices simply referred to just as clickers. PI could be applied using simpler and cheaper equipment, for example just by raising hands, but the clickers have clear benefits $[19,20]$. First of all, the answering is anonymous, making it easier also for the shy and insecure students to participate. Usually the clickers come also with polling software, which presents a diagram of the distribution of the students' answers in real time. This allows, or actually forces, the teacher to adapt the teaching according to the students' responses. If the question appears very easy, no discussion is required. If, on the contrary, a wrong answer still dominates after the discussion, a further recap of the subject is needed leading to agile teaching [19].

As a method, PI seemed very promising, since the goal was to activate and engage the students in interaction. The students cannot only passively listen to the teacher, but they have to think and respond to the questions themselves. Communication and discussion between the students is required. Moreover, the role of conceptual understanding was to be emphasized. Questions and conversation help students to identify incorrect understanding and gaps in their knowledge.

To ensure that students study the subject before coming to class and that the entire course material is covered to the same extent as in the traditional lecture course, prestudy reading as a homework assignment was given before every session. Each time they were asked to submit their answer to three questions, which were graded. Two of them were related to the considered topic, such as, "What are eddy currents and how are they generated?", "How do you define the polarization of an electromagnetic wave?" or "What kind of different waveguides exists and where are they used?" The third question was always the same as the reading incentives presented in [18]: "What did you find difficult or confusing about the reading? If nothing was difficult, tell us what you found most interesting." These pre-study assignments were the only part in PI method that affected the course assessment. Participation in the actual PI sessions was voluntary and polling was anonymous.

Nevertheless, the most crucial challenge was, again, to find and develop reasonably good multiple-choice questions, as they, regardless of the applied technology, eventually determine the success and relevance of the whole method. The questions were adopted from several sources and some were modified or written by the teacher himself with help from colleagues. The most valuable sources for questions and ideas were [17], [22], and the additional online material for [21]. Altogether 33 multiplechoice questions were used during the eight teaching sessions. All these sessions did not only consist of PI, as for instance, sometimes exercise solving was included. The minimum number of questions per session was two and the maximum was seven. In the following, two example questions formulated by the authors and used on their course are presented.

\section{Example question 1:}

According to Faraday's law, a time-dependent magnetic flux density $B(t)=B_{0} \cos (\omega t)$ induces an electromotive force in a rectangular conducting loop. Assume the flux is perpendicular to the plane of the loop. If the side length of the loop is doubled, but simultaneously the amplitude of the flux halves, the induced electromotive force
A) drops to one quarter
B) halves
C) remains unchanged
D) doubles
E) quadruples

The correct answer is D. Before the discussion the votes were distributed over several choices, but after the discussion a clear majority has found the correct alternative (see Figure 1). This example clearly shows the efficiency of the peer discussion. The number of students who answered this question was 16 .

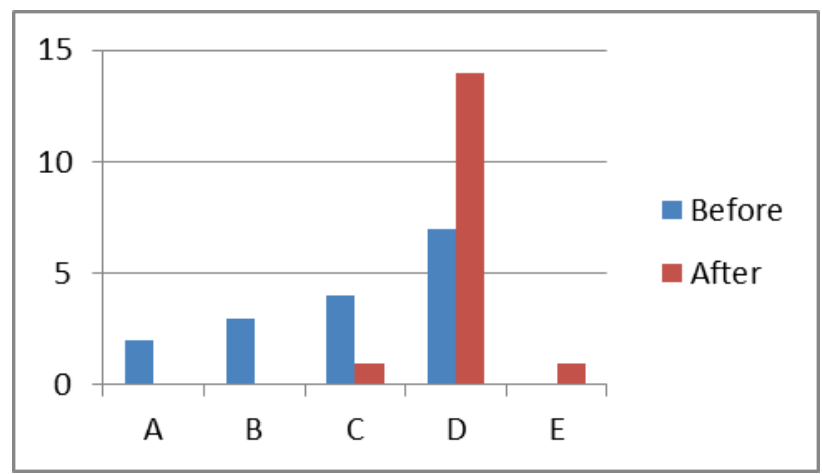

Figure 1. Answers to question 1 before and the after the peer discussion.

Due to the small number of students on the course, it is questionable to draw any statistically valid quantitative conclusions of the method. However, considering the 21 questions that followed the full PI procedure the method worked as expected in 17 questions, i.e., the correct answer won the polling after the discussion with gains [12] between $33 \%-100 \%$. It must be noted that the small number of students causes the large range of variation in gain, which must be considered only as a suggesting measure. Nevertheless, the results are consistent with results presented in literature.

\section{Simulation exercises}

In addition of the theory and crucial concepts, numerical software was studied during the course in order to strengthen professional skills. The AWR Design Environment (AWRDE) circuit simulator [23] was used to analyze circuits and electromagnetic fields were simulated with the COMSOL Multiphysics program. Matlab was also utilized as a tool for numerical calculations.

\section{Example of a Comsol Multiphysics simulation ex-} ercise:

Use the Comsol Multiphysics software to model the soda can which is half filled with liquid. Compute the lowest resonance frequency as a function of permittivity of the liquid in the following two cases: A) The can is upright and B) the can is on it's side

The students especially enjoyed this simulation project. The visualization using numerical software aimed to focus the learning on understanding the phenomena, making the electromagnetic fields visible, which otherwise human eye cannot see. Getting to know computational software that is actually used in professional life was found to be very 
motivating. The student feedback presented in Section IV supports these remarks.

\section{Laboratory measurement}

Practical measurements were used to familiarize students with laboratory equipment and to motivate studying theory. As an example of a two-port, the third-order Butterworth low-pass filter was studied by measuring, doing calculations, and with simulations. Both y parameters and driving-point functions were considered.

\section{Example:}

Measure the $\mathrm{z}$ parameters of the low-pass filter in Figure 2 at $300 \mathrm{kHz} . R_{\mathrm{g}}=50 \Omega, C_{1}=C_{3}=4.7 \mathrm{nF}$ and $L_{2}$ $=100 \mu \mathrm{H}$.

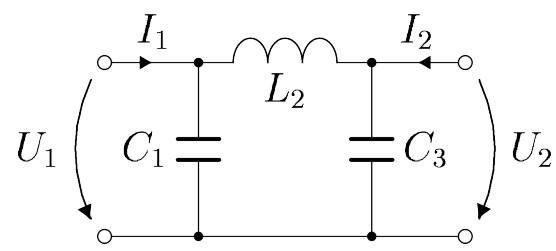

Figure 2. Third-order Butterworth low-pass filter

The students considered that the laboratory measurements as well as simulations connected the theoretical calculations to practice.

\section{E. Design exercise}

A couple of larger design exercises were given to students in order to motivate to study theory. In these exercises, applying the taught knowledge was required in order to find a good solution to the problem. Knowledge from both field theory and from circuits (transmission line analogue) must be combined so that a matching for a multilayer interface in the following problem is found.

\section{Project work 3: Transmission lines, reflection,} transmission, and the TEM wave

The multilayered boundary surface is to be matched such that an IR-B plane wave $(f=200 \mathrm{THz})$ incident normally from the left does not reflect from it. The refraction coefficient of the material to be used in the matching layer is $n_{2}=2$. What should be the thickness $d_{2}$ of the layer? Is this layer sufficient or is another matching layer necessary? If necessary, what is its thickness $\mathrm{d} 1$ if its refraction coefficient $n_{1}=1.5$ ? The boundary surface has air $\left(n_{0}=1\right)$ on either side and the material used is non-magnetic $\left(\mu=\mu_{0}\right)$ and lossless. Use the Smith chart (transmission line analogy) to solve the problem, and check your solution by determining the transmission matrix $\mathbf{K}$ and then computing the reflection coefficient $R$.

How much of the incident power is transmitted through the matched boundary surface?

As another example, the following antenna design exercise with multiple solutions encourages students to integrate their ideas and supports collaboration. Matlab was used for the calculations.

\section{Project work 6: Antennas.}

The transmission broadcast at $f=10 \mathrm{MHz}$ and arriving from $30^{\circ}$ north of east, as shown in Figure 3, is to be received using vertical monopole antennas. Based on the image principle, these antennas radiate like dipoles when erected from the ground. Thus an antenna on the surface of the earth radiates omnidirectionally. Hence the reception is to be made more effective by building an array of $\mathrm{N}$ elements. The array is deemed to be good enough when the half-power beamwidth of its main lobe is at most $22^{\circ}$. However, the situation is complicated an interfering signal of the same frequency arriving from the opposite direction, that is from $30^{\circ}$ south of west, and whose signal strength is to be attenuated at least by $30 \mathrm{~dB}$ compared to the desired signal.

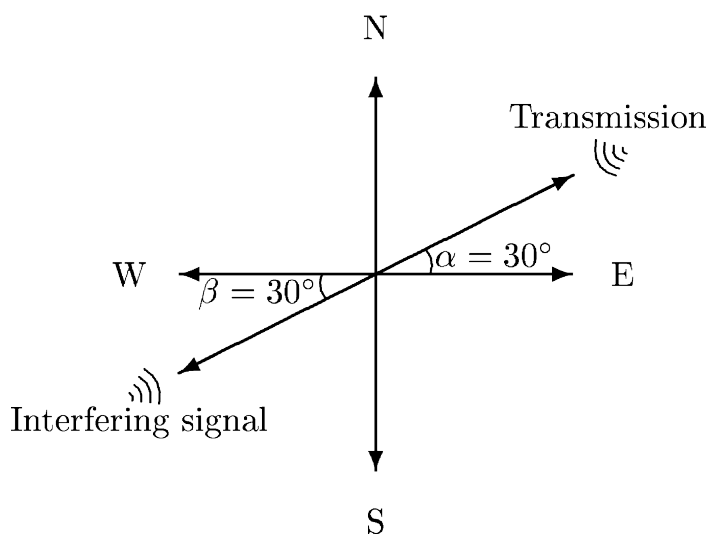

Figure 3. Antenna project work

The team's objective is to design an antenna array fulfilling these conditions and to plot the farfield radiation pattern using Matlab. What is the smallest number of elements capable of having a sufficiently narrow beam in the correct direction? How, in this case, should the elements be positioned and by how much are they separated from each other? What phase shift $\delta$ would possibly be required between the elements?

Generally Matlab was considered useful. However, for some students writing their own Matlab scripts appeared to be challenging. The students also stated that plotting the radiation patterns themselves helped them better understand the principles of antenna radiation

\section{Evaluation OF StUdents}

Assessment has a significant influence on learning. To motivate students, working during the course and homework were an essential part of the assessment, i.e., participating in the laboratory measurements and simulation exercises affected the grade. In the evaluation, the value of the exams was only $40 \%$ and $60 \%$ of the total points was collected through course work. The limit for an accepted achievement was $50 \%$, i.e. passing the course without the exam was possible. The final grade was determined as follows:

- $40 \%$ exam problems (5 exam problems from certain topics during the exam periods)

- $15 \%$ participation in classes, laboratory measurements, simulation exercises etc.

- $45 \%$ homework and projects returned during the course, examples presented in the previous section.

In order to emphasize the significance of the cooperation between students, over $30 \%$ of the evaluation was from the collaborative work. Nevertheless, even though the collaboration improves motivation and engagement to the studies, the knowledge of an individual student is not automatically increased through cooperation. Therefore, to 


\section{SPECIAL FOCUS PAPER \\ Promoting ACTIVE LEARNING IN ELECTRICAL ENGINEERING BASIC STUDIES}

verify the skills of each student separately, assessment was mainly based on the individual's achievements.

\section{A. Learning results}

The group of EPOP students was quite a heterogeneous group, and many of them have delayed their studies. In spite of this, everybody passed the course and almost all examination results were better than in the traditional lecture-based course!

Seven examination tasks common to the normal lecture courses were given to the EPOP students, four calculation problems and three concept questions. The first three tasks were about circuit analysis. Task 1 was a transient analysis problem, and task 2 was a problem about the behavior of transmission lines in the time domain. The third task was concept questions about transmission lines in the frequency domain. Tasks 4-7 were about dynamic field theory. The fourth task was a concept question about power transfer and the task 5 was a problem on the timeharmonic plane wave. The sixth and the seventh tasks were concept questions and calculation problem about antennas.

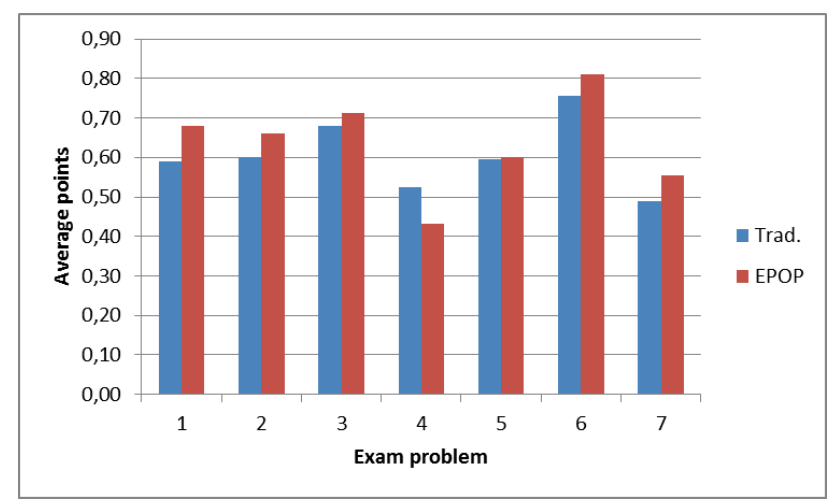

Figure 4. Scaled average results of examination problems (max. 1)

Figure 4 shows the scaled average results of all the problems. Because of the scaling, the grades resulting from these problems were slightly differently weighted, but this presentation is only for comparing the results. The results showed that the EPOP students obtained better results in all tasks except in task 4. The reason for this is that the topic of task 4 was treated in detail in the traditional lectures but was not so heavily emphasized in the EPOP course.

However, some care has to be taken when interpreting the results. Even though the examination problems and concept questions were the same for both the EPOP and traditional course students, the time used per question was slightly different, and the traditional students had more questions in a wider range of the subjects. This possibly favors EPOP students a little. In addition, the EPOP group was small and therefore very significant conclusions cannot be made about the learning results. When comparing the results, it should be also noted that this new collaborative teaching given in a small group demands more resources. In any case, the effect of the extra effort compared the achieved improvement has to be evaluated separately.

The main result of this analysis is that although the IE teaching was not so calculation-oriented than the traditional lecture-based teaching, the success of the EPOP students in the calculation problems in the examinations was not poor even when the discussion above is taken into consideration.

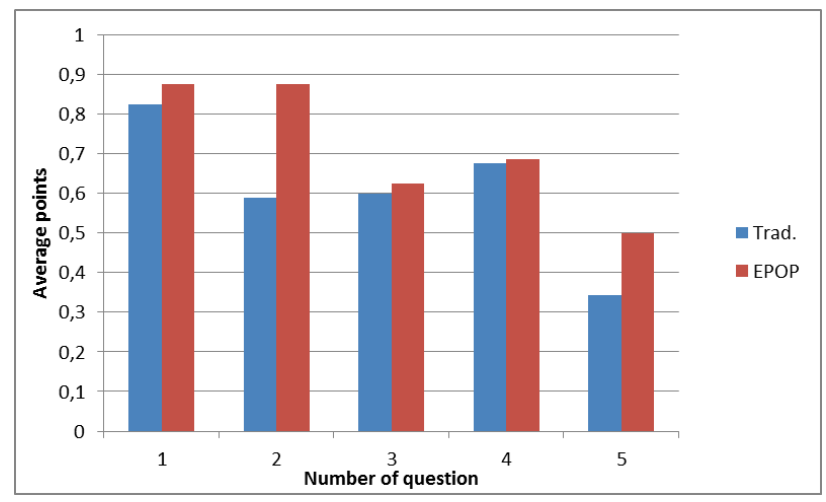

Figure 5. Scaled average results of the multi-choice questions (maximum 1)

The results of the multi-choice questions are presented in the Figure 5. The EPOP students got better results from every question, and the same questions were easy (number 1) or difficult (number 5) for both of the groups. Both groups made the same mistake in question 5 . The main reason was the misleading formulation of the answer alternatives.

\section{B. Student feedback}

All students were interviewed after the EPOP course. Some examples of their comments (translated to English) are presented in the following to indicate how the students experienced the project. One of the goals of the EPOP course was to shift the focus from the mathematics to the understanding of phenomena and conceptual thinking. This was also recognized by the students, as this comment implies:

A: Yeah, I mean, it ain't enough you just do the math. You gotta understand what you're calculating.

The group creates positive pressure to be active and increases engagement and motivation to learning. The following comment tells that peer support encourages working regularly.

A: I dunno, like I have this... in this project I mean, what should I say, like maybe this small peer pressure; like you don't wanna leave your mates in the lurch and so on. So I do what I said, like promised to do, 'cos of the others. Like it's hard getting motivated when you're like alone, you know. But when your mates are around you, you know, it's kinda easier to get it. Motivated, I mean. At least I have noticed this here and in my other life.

Starting studying already at the beginning of the course and keeping it up regularly during the entire course is very demanding for some students. Students need help and enforcement to do that, and continuous evaluation is a good trick to do it.

A: Well, at least that's just how it is (--) they just improve my working habits. Like when you often still really leave it easily... work at the last minute, so then you think that in this kind of interaction that you're less lazy. And 
then, yeah, you notice sort of that you're a tight team like, then sort of you go to class, you know, just'cos it's cool fun, like.

The interaction with staff is very important for students:

A: Here's the teacher who knows your name and I know his name. And I can like ask, and everything's informal.

The simulation software skills have been noticed to be motivating, because they (and measurement skills, as well) are considered be useful in the professional life to come. Also, the visualization in the simulations have been regarded as an important feature.

A: It was interesting being able to check out these programs. I guess that in professional life they use these simulators in practice. So it's not bad at all to be able to get to use them at this stage. I'd never ever used any simulation software before.

A: Yeah, it's the same in Comsol when you see just that, where the field is the strongest and such.. It's always somehow like when you see the formula, you don't know anything at all [what it's saying].

\section{DISCUSSION}

The project has several objectives as listed in Section II. This section gathers the most important observations and insights of the teachers. Also, the influence of the project on teaching now and in the future is assessed.

The student interviews indicate that collaboration was useful for all students; both successful, advanced students as well as worse students needing more help in exercises benefit from interaction. Similar results were reported also in [24]. The best students strengthen their understanding of concepts when explaining issues to other students. Although calculating and solving problems together was observed to improve motivation, guidance is necessary so that students really cooperate instead of individual thinking and copying at the same table. Time is required for thinking about the problem before starting the conversation and working together [25]. Special attention should be paid to the type of the exercises used and also to the atmosphere in class so that they promote collaboration instead of individual working and competition. In spite of these challenges, the teachers experienced that during the course the students turned from individuals to group members. Instead of protecting their own ideas, students started to share their thoughts with others and help each other to improve their understanding. This success can be read also from the many student feedback comments.

Promoting effective collaboration and creating conditions that support enhancement of academic skills is not straightforward [6]. For example, group division is an issue to be aware of as suggested by the hints and remarks in $[25,26]$. An easy and safe solution is to draw lots to assign the groups and to change them often. This way nobody needs to suffer from a dysfunctional group for too long. Popular practice that students self-organize into groups is not the best solution from the point of view of learning and teaching. Sometimes friendly relationships can complicate fair division of responsibility and work load in the group. Groups with heterogenic abilities are often the best for learning.

The project showed that continuous evaluation and the possibility to follow the accumulation of the points throughout the course motivated students a lot, i.e., the evaluation should be something other than just a final exam. Long-term assessment increases the engagement with the learning process, and working continuous naturally improves the learning results. Moreover, there is no reason to be afraid of giving hard problems to students with insufficient prerequisites, if they receive enough support and guidance is available. Hard work is not a source of suffering, but rather a way to give resources to win difficulties, to improve self-confidence, and a starting point for insights. That the teacher sets high expectations for their achievements, is an important signal to the students.

Although applying PI with clickers works well, collaboration itself is more important. Instead of individual technical concepts, the main focus should be in activating thoughts, encouraging conceptual thinking, promoting conversation between students, and giving fast feedback. Clickers work as an effective stimulus for these objectives.

Because the manner in which the curriculum is implemented in practice seems to be much more important than its actual form or content [16], more attention is focused on teaching methods and engagement to add interaction and collaboration.

\section{CONCLUSION}

The EPOP teaching project gave the possibility to test and evaluate many important aspects in teaching basic courses. Especially, it was noted that both the most talented, successful and advanced students as well as those who just wanted to pass the course benefited from collaborative interactive engagement teaching and found it motivating. In addition, the success of the EPOP students in the examinations was at the same level as the students who participated in the traditional, more calculationoriented teaching.

\section{ACKNOWLEDGMENT}

The authors would like to thank Tuomas Leinonen and Ville Kivijärvi for their skilled testing and for developing the project work used in EPOP course. The authors are also grateful to Luis Costa for helping with student comment translations and commenting on the paper.

\section{REFERENCES}

[1] M. Guzdial, P. Ludovice, M. Realff, T. Morley, K. Carroll, and A. Ladak, "The challenge of collaborative learning in engineering and math," in Proc. IEEE of Frontiers in Education Conference 2001, Reno, Nevada, oct 2001.

[2] G. S. Stump, J. C. Hilpert, J. Husman, W.-T. Chung, and W. Kim, "Collaborative learning in engineering students: Gender and achievements," Journal of Engineering Education, vol. 100, no. 3, pp. 475-497, 2011. http://dx.doi.org/10.1002/j.2168-9830.2011. tb00023.x

[3] M. E. Besterfield-Sacre, C. J. Atman, and L. J. Shuman, "Characteristics of Freshman Engineering Students: Models for Determining Student Attrition and Success in Engineering," Journal of Engineering Education, vol. 86, no. 2, pp. 139-149, 1997. http://dx.doi.org/10.1002/j.2168-9830.1997.tb00277.x

[4] D. W. Knight, L. E. Carlson, and J. F. Sullivan., "Improving engineering Student Retention through Hands-On, Team Based, 


\section{SPECIAL Focus PAPER \\ Promoting Active LeARning In Electrical ENGINEERING BASIC Studies}

First-Year Design Projects", Proceedings 31st International Conference on Research in Engineering Education, ASEE, June 2224, 2007, Honolulu, HI

[5] C. F. Yokomoto, M. E. Rizkalla, C. L. O’Loughlin, and N. P. Lamm, "Developing a Motivational Freshman Course Using the Principle of Attached Learning," Journal of Engineering Education, vol. 88, no. 1, pp. 99-106, 1999. http://dx.doi.org/10.1002/j.2168-9830.1999.tb00418.x

[6] K. A. Smith, S. D. Sheppard, D. W. Johnson, and R. T. Johnson, "Pedagogies of Engagement: Classroom-Based Practices, Journal of Engineering Education”, vol. 94, no. 1, pp, 87-101, 2005.

[7] L. R. J. Costa, M. Honkala, and A. Lehtovuori, "Applying the Problem-Based Learning Approach to Teach Elementary Circuit Analysis," IEEE Tran. Edu, vol. 50, no. 1, pp. 41-48, Feb. 2007. http://dx.doi.org/10.1109/TE.2006.886455

[8] M. Wanous, B. Procter, and K. Murshid, “Assessment for learning and skills development: the case of large classes," European Journal of Engineering Education, vol. 34, no. 1, pp. 77-85, 2009. http://dx.doi.org/10.1080/03043790902721462

[9] A. Astin, What matters in College? Four Critical Years Revisited, San Francisco, Cal, Jossey-Bass, 1993.

[10] B. Barron, When Smart Groups Fail, The Journal of the Learning Sciences, 12(3), pp. 307-359, 2003. http://dx.doi.org/10.1207/ S15327809JLS1203_1

[11] J. Leppävirta, "Engineering students' proficiency in electromagnetic", Doctoral Dissertation, Aalto University, 2011.

[12] R. R. Hake, "Interactive-engagement versus traditional methods: A sixthousand-student survey of mechanics test data for introductory physics courses," American Journal of Physics, vol. 66, pp. 64-74, 1998. http://dx.doi.org/10.1119/1.18809

[13] M. J. Prince and R. M. Felder, "Inductive teaching and learning methods: Definitions, comparisons, and research bases," J. Engr. Education, vol. 95, pp.123-138, 2006. http://dx.doi.org/ 10.1002/j.2168-9830.2006.tb00884.x

[14] A. Sihvola, J. Leppävirta, and H. Kettunen, "Sign, curls, and time variations: learning to appreciate faraday's law," Advanced Electromagnetics, vol. 1, no. 1, pp. 1-5, 2012. http://dx.doi.org/ 10.7716/aem.v1i1.69

[15] C. S. MacLatchy, P. Backman and L. Bogan, "A quantitative magnetic braking experiment, “ Am. J. Phys., vol. 61, pp. 10961101, December 1993. http://dx.doi.org/10.1119/1.17356

[16] C. Chiaverina, "The simplest motor?" Phys. Teach., vol. 42, p. 552, December 2004. http://dx.doi.org/10.1119/1.1828728

[17] E. Mazur, Peer instruction: a user's manual. New Jersey: Prentice Hall, 1997.

[18] C. H. Crouch and E. Mazur, "Peer instruction: Ten years of experience and results," Am. J. Phys., vol. 69, pp.970-977, September 2001. http://dx.doi.org/10.1119/1.1374249
[19] D. Bruff, Teaching with Classroom Response Systems, San Francisco, CA: Jossey-Bass, 2009.

[20] R. H. Kay and A. LeSage, "Examining the benefits and challenges of using audience response systems: A review of the literature," Comput. Educ., vol. 53, pp. 819-827, November 2009. http://dx.doi.org/10.1016/j.compedu.2009.05.001

[21] B. M. Notaroš, Electromagnetics, Upper Saddle River, NJ: Pearson, 2011.

[22] Concept Tests and Course Materials from CU Boulder, available online: http://www.colorado.edu/physics/EducationIssues/cts/ind ex.htm

[23] AWR, http://web.awrcorp.com.

[24] L. E. Keiner and T. E. Burns, "Interactive engagement: How much is enough?" The Physics Teacher, vol. 48, pp. 108-111, 2010. http://dx.doi.org/10.1119/1.3293658

[25] B. Oakley, R. M. Felder, R. Brent, and I. Elhajj, "Turning student groups into effective teams," Journal of Student Centered Learning, vol. 2, no. 1, pp. 9-34, 2004.

[26] R. M. Felder and R. Brent, "Effective Strategies for Cooperative Learning," Journal of Cooperation and Collaboration in College Teaching, vol. 10, no. 2, pp. 69-75, 2001.

\section{AUTHORS}

A. Lehtovuori is with Aalto University School of Electrical Engineering, P. O. Box 13000, 00076 Aalto, Finland (e-mail: anu.lehtovuori@aalto.fi).

M. Honkala is with Aalto University School of Electrical Engineering, P. O. Box 13000, 00076 Aalto, Finland (e-mail: mikko.a.honkala@aalto.fi).

H. Kettunen was with Aalto University School of Electrical Engineering. He is now with the University of Helsinki, P. O. Box 68, 00014 Helsinki, Finland (e-mail: henrik.kettunen@helsinki.fi)

J. Leppävirta was with Aalto University School of Electrical Engineering. She is now with Outotec, Espoo, Finland (e-mail: johanna.leppavirta@outotec.com)

This article is an extended and modified version of a paper presented at the EDUCON2013 conference held at Technische Universität Berlin, Berlin, Germany from March 13-15, 2013. Received 04 April 2013. Published as resubmitted by the authors 21 May 2013 